IV Congreso Internacional Estética y Política Poéticas del desacuerdo para una democracia plural 16 y 17 de octubre. Valencia

Doi: http://dx.doi.org/10.4995/CEP4.2019.10292

\title{
Touki Bouki: (des)encuadres políticos de la diáspora estética
}

\author{
Marina Riera Retamero
}

Universidad de Barcelona. m.riera@ub.edu

\begin{abstract}
The paper proposes an approach to the film Touki Bouki (1973) by the senegalese director Djibril Diop Mambéty. As epistemological frame I use concepts from Jacques Rancière's philosophy to explore the film in its own ambivalence between: (1) representational images from a post-Independance context in Dakar (Senegal); and (2) a metaphor of the diaspora representations toward an "aesthetic diaspora» (Peffer, 2013). I explore the film as a displacement from discursive political practices to aesthetic political practices. The film is not made of documentary images, as the militant cinema or Third Cinema does; but it's made of aesthetic and fictional identification forms able to avoid colonial logics. is îp Finally, I aim to explore the staging of the film as a reassembly of visual resources and tools from the nouvelle vague with a political and social apparatus of visibility that defies the historiographic logic of colonial subalternity and goes beyond the dicotomic discourses of master-slave / oppressor-oppressed.
\end{abstract}

Keywords: politics, aesthetics, decolonialism, cinema, diaspora, fiction, documentary.

\begin{abstract}
Resumen
La presente comunicación propone un acercamiento al filme Touki Bouki (1973) del director senegalés Djibril Diop Mambéty, utilizando conceptos y figuras sensibles de la filosofía de Jacques Rancière como prisma epistémico para explorar el filme desde su ambivalencia entre: (1) imágenes representacionales de un contexto post-Independencia en la ciudad de Dakar (Senegal); y (2) la traslación de los espacios de la diáspora hacia una «diáspora estética» (Peffer, 2013). Asimismo, pensar el filme en su calidad política como una propuesta de desplazamiento hacia un conjunto de prácticas políticas no discursivas, sino estéticas. Ya no son las imágenes documentales propias de la militancia del Tercer Cine; sino la correspondencia entre formas de identificación estéticas capaces de desactivar las lógicas coloniales. Por último, me propongo explorar la puesta en escena del filme como un reensamblaje de los recursos propios de las nouvelle vague con un dispositivo político y social de visibilidad que desafía la lógica historiográfica de la subalternidad colonial y que va más allá de la retórica dicotómica amo-esclavo / opresor-oprimido.
\end{abstract}

Palabras clave: política, estética, decolonialidad, cine, diáspora, ficción, documental. 


\section{Introducción y objetivos}

Touki Bouki (1973) es seguramente la obra más conocida del senegalés Djibril Diop Mambéty. Nacida trece años después de la Independencia de Senegal, en 1973 el filme recibió el premio de la Crítica Internacional en el Festival de Cannes y el premio del Público en el Festival de Moscú (Africine, 2013). La presente comunicación pretende explorar las estrategias estéticas, narrativas y significantes del filme, utilizando como prisma epistémico algunas figuras sensibles de la filosofía de Jacques Rancière $(2001,2003,2011)$ y regímenes estéticos de Deleuze $(1983,1985,1988)$, en sí de texturizar y explorar los siguientes interrogantes:

(1) ¿Cómo se articula la ficción del filme en tanto que operación de disenso a los relatos dominantes? ¿Qué relaciones y tensiones se establecen entre ficción, imagen y memoria? ¿Puede la ficción reensamblar aquellos relatos y formas de vida descartadas por la lógica colonial?

(2) ¿Qué formas estéticas y poéticas utiliza el filme para pensar la diáspora y la migración? ¿Cómo traslada un régimen representacional hacia un régimen estético para generar un relato visual? ¿Qué correspondencia estética y sensible hay entre la película y las producciones visuales de la nouvelle vague francesa? ¿Qué conexiones y desconexiones hay entre el filme y el cine militante?

(3) ¿Qué dispositivos políticos y sociales de visibilidad pone en marcha la película? ¿Existe un desplazamiento de las formas de política discursiva hacia políticas estéticas? ¿Cómo interfiere esta configuración de lo político en el relato colonial? ¿Cómo desafía la lógica de la subalternidad?

\section{Desarrollo}

\subsection{Ficción y disenso. Descolonizar la memoria}

Entendamos aquí la ficción desde una perspectiva ranceriana: no se trata de la fantasía que pretende oponerse a la realidad o hacerse pasar por ella, sino que, al contrario, "la ficción es la construcción, por medios artísticos, de un «sistema» de acciones representadas, de formas ensambladas, de signos que se responden" (Rancière, 2001, p. 182). En este caso, la ficción no pretende un efecto de veracidad o de dotar de «mayor realidad» a una situación determinada (Sontag, 2003), sino que se configura como interrupción u operación de disenso (Rancière, 2003) a la tendencia hegemónica. Su radicalidad se mide en los desafíos y los posibles que dibuja (Garcés, 2002).

Dice Gloria Anzaldúa: "el lenguaje de las imágenes precede al pensamiento articulado en palabras; la mente metafórica antecede a la consciencia analítica." (Anzaldúa, 1987, p. 124). La película no se construye de forma discursiva, sino decididamente sensible. Existe un juego de correspondencias entre las imágenes de corte documental [degollamiento y desollado del ganado/ mujer vendiendo fruta en el mercado] y reencadenamientos de corte irracional (Deleuze, 1985) [montajes-cut de la sangre del ganado, el mar, los cuerpos de Anta y Mory/ dislocaciones temporales y déjà vu]. Esta correspondencia sacrifica todos los efectos sintéticos de la imagen (Deleuze, 1985) como documento etnográfico y designa un diálogo poético entre distintas co-presencias y realidades sociales. Establece "un mouvement dialogique au sein duquel elle est l'objet d'une dialectique, de négociations de réalités antagonistes découlant de la colonisation [...] et témoignant de l'émergence de nouvelles identités culturelles." (Chérel, 2015, p.34).

"La fórmula de Godard «no es sangre, es rojo»", dice Deleuze, "cesa de ser únicamente pictórica y cobra un sentido propio del cine" (Deleuze, 1985, p. 38). La ficción cinematográfica entonces, decreta una política del sentido (Rancière; Soto-Calderón; Bassas, 2018) y una pedagogía propia. A ésta, entrelazada con las transformaciones sociopolíticas de su presente, se le confiere la capacidad, ya no de conservar o acumular una historiografía colonial (Spivak, 1985) que conceptualiza la descolonización y la migración en términos de centro (Francia) y periferia (territorios colonizados del Sur) (Abderrezak, 2016); ni tampoco de ilustrar las formas de resistencia militante que se revelan contra este orden (Mezzadra; Nelson, 2013) como acontecimientos localizados. Al contrario: "se instala en el hueco que separa la construcción del sentido, lo real referencial y la heterogeneidad de sus «documentos»" (Rancière, 2001, p. 185), creando una memoria viva que se sabe emancipatoria en tanto capaz de burlar y suspender los efectos de la condición subalterna que le asigna el orden colonial. 


\subsection{Hacia una diáspora estética}

Las prácticas del cine militante parecen establecer una correlación directa entre las formas de resistencia y los procesos de descolonización de comunidades subalternizadas con imágenes documentales (Abderrezak, 2016), representacionales y con narrativas históricas o contra-históricas (Veliz, 2010) sujetas a una inmediatez ética (Rancière, 2010) propia de los discursos estructurados desde la lógica y las palabras; y no desde la sensorialidad y política de las propias imágenes. Pero como nos señala Gloria Anzaldúa: "una imagen es un puente entre la emoción evocada y el conocimiento consciente; las palabras son los cables que sostienen el puente" (Anzaldúa, 1987, p. 124). Asimismo, Rancière nos advierte que "la eficacia del arte no consiste en transmitir mensajes, ofrecer modelos o contra-modelos de comportamiento o enseñar a descifrar representaciones. Consiste antes que nada en disposiciones de los cuerpos, en recortes de espacios y de tiempos singulares que definen maneras de estar juntos o separados, frente a o en medio de, dentro o fuera, próximos o distantes." (Rancière, 2008, p. 59).

Esto no conlleva ni la invalidez de la variedad de miradas y subjetividades que genera el activismo respondiendo a exigencias situadas (Veliz, 2010); ni tampoco implica "la ilusión de que cada una de ellas constituye un mundo" (Garcés, 2002, p. 96). Al contrario: "pasamos de un mundo sensible a otro mundo sensible que define otras tolerancias e intolerancias, otras capacidades e incapacidades." (Rancière, 2008, p. 70). En este sentido, abrir mundos sensibles es un acto político porque conlleva renegociaciones en la esfera común. En palabras de Deleuze: "ninguna filosofía ha llevado tan lejos la afirmación de un solo y mismo mundo, y de una diferencia o variedad infinitas en este mundo." (Deleuze, 1988, p. 78).

Touki Bouki no crea un mundo imaginario basado en una nostalgia retro-utópica ni tampoco en un relato revolucionario determinante. Su desafío es el de afirmar una escapada al lugar que se le supone (Rancière, 2011) y omitir su esperada reacción al poder y a las formas de dominación, tejiendo un relato estético, afectivo e irracional: "este reino del juego y de la apariencia, que también se diferencia del reino del poder, promete más libertad. Su principio fundamental es, de acuerdo con Schiller, dar libertad por medio de la libertad." (Han, 2005, p. 41). Mambéty explora los espacios de la diáspora africana desde otras formas disensuales de comprensión estéticas y sensibles. El mismo Mambéty dijo: "je me suis concentré sur la notion de liberté, qui comprend la liberté de ne pas savoir." (Mambéty, 1999, p. 4).

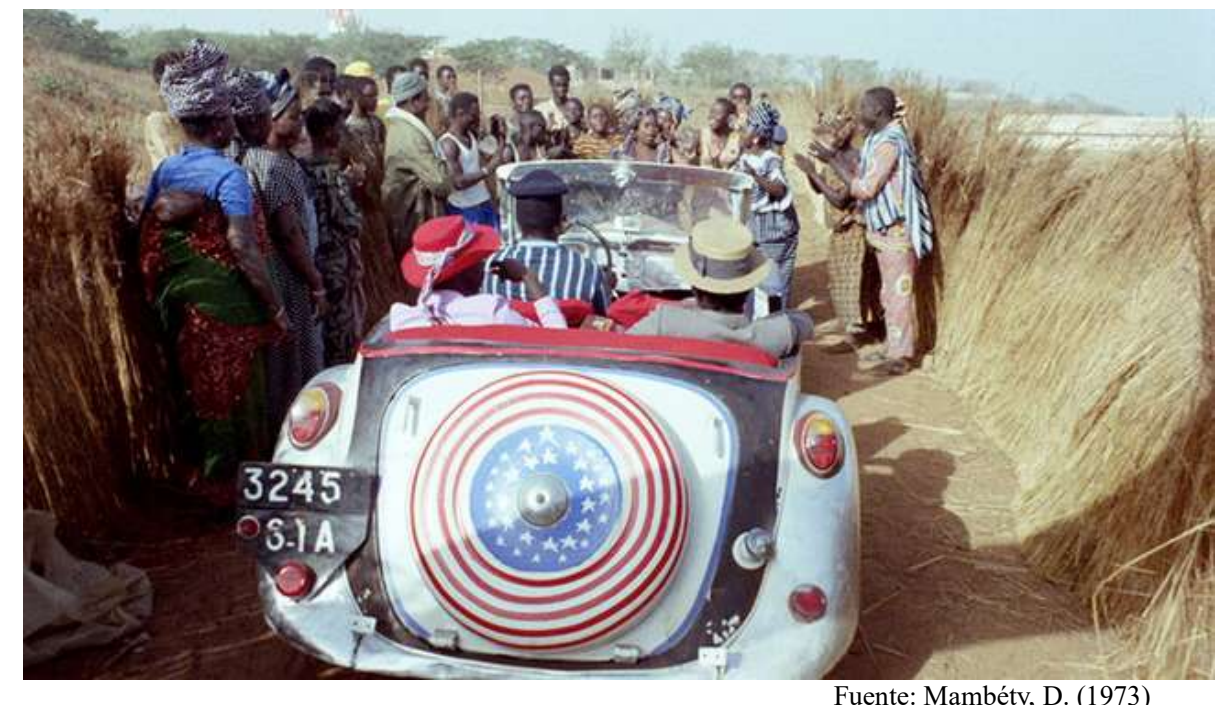

Fig. 1: Fotograma del filme Touki Bouki

De la tensión entre esta indeterminación y libertad se infiere la configuración de un dispositivo de visibilidad. SotoCalderón, acudiendo a Rancière y a Lyotard, apunta hacia "una comprensión de lo indeterminado como una 
extraterritorialidad para descubrir nuevos disensos, nuevas maneras de lucha, pero no para configurar nuevos terrenos sólidos, previamente delimitados o que puedan ser especulados desde una previsión, sino que su propuesta consistiría, precisamente, en explorar espacios metamórficos y de tránsito.” (Soto-Calderón, 2013, p. 10). El montaje del filme ofrece una serie de estrategias que trastocan los esquemas previamente delimitados bajo una lógica lineal. Por un lado, dislocaciones temporales de secuencias sin aparente correspondencia narrativa [(1) ankoles hacinados, agonizantes, tirados por cuerdas / (2) Anta corre por un despeñadero para buscar a Mory herido / (3) el movimiento de las olas del mar, los cuerpos de los protagonistas tendidos sobre las rocas]; por otro lado, subtramas de corte teatral en las que los deseos y delirios de los protagonistas interfieren a modo de apariciones sobre la trama principal, desencajando cualquier esquema previsible (Fig. 1). En este caso no tiene sentido discernir entre la trama argumental y sus co-relatos imaginarios. Al contrario, como apuntaba Deleuze sobre el montaje en Vertov: "es su indiscernibilidad lo que va a dotar a la cámara de un rico conjunto de funciones, engendrando una nueva concepción del cuadro y de los reencuadres.” (Deleuze, 1985, p. 39).

\section{3. (Des)encuadres políticos}

En la película, el viaje migratorio se traza bajo el móvil del deseo, y no de la desesperación. Aquí el deseo aparece como modo impulsivo y corpóreo de interrogación. En palabras de Judith Butler "expresa la relación del sujeto con aquello que él no es, con lo diferente, lo extraño, lo nuevo, lo esperado, lo ausente, lo perdido. Y la satisfacción del deseo es la transformación de la diferencia en identidad.” (Butler, 1987, p. 39). El deseo confiere a los personajes una sensibilidad política que no responde a discursos constituidos: "elles son choisi d'explorer son émancipation du contrôle colonial en se détachant de ce qu'elle identifiait comme mentalité colonisée et vieilles coutumes transmises par les autorités politiques et familiales, mais sans se confronter ni à l'idéologie marxiste, ni au révisionnisme traditionnel des théoriciens de l'indépendance." (Chérel, 2015, p. 35). Mambéty no trata de ofrecer un relato sobre una vida difícil, sino al contrario, de su ensayo se infieren dos posibles: (1) reensamblar subjetividades y sensibilidades movidas por un deseo común; y (2) recolectar "la riqueza contenida en la experiencia de la colonización, la rebelión y la inmigración" (Rancière, 2008, p. $83)$.

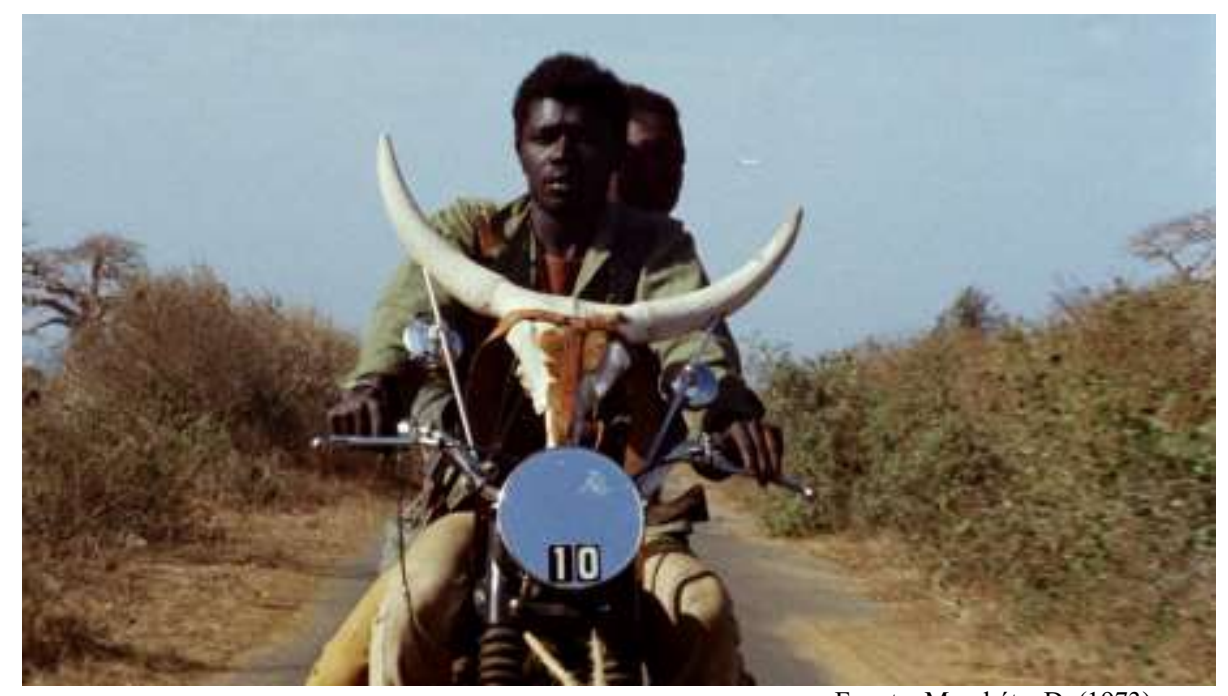

Fuente: Mambéty, D. (1973)

Fig. 2: Fotograma del filme Touki Bouki

La radicalidad de la narración reside en una supresión: su disposición estética consigue evitar la victimización o representaciones subalternizadas, explorando formas de deseo y de posibles: "tels Bonnie and Clyde, à l'instar d'autres jeunesses du monde, ils semblent tous deux en déshérence, fascinés par l'aventure, la richesse, ses illusions et ses possibles." (Chérel, 2015, p. 31). Esta disposición toma la forma de road movie [el tránsito de los protagonistas sobre una 
motocicleta con cornamenta de ankole por los alrededores de Dakar (Fig. 2) / las líneas sonoras entrecortadas de Joséphine Baker cantando en bucle "París, París, París"]. Lo que hace aquí el montaje de las imagenes es "llevar la percepción a las cosas, poner la percepción en la materia, de tal manera que cualquier punto del espacio perciba él mismo todos los puntos sobre los cuales actúa o que actúan sobre él, por lejos que se extiendan esas acciones y esas reacciones" (Deleuze, 1983, p. 86).

En su alegato por reensamblar política y estética, Rancière proponía la siguiente figura: "que la frontera esté siempre presente y que no obstante ya se haya atravesado." (Rancière, 2005, p. 40). Así pues, el filme deja entrever que no se trata de una elección técnica, sino política: el montaje desafía las formas consensuadas de representación de la migración y añade otras formas estéticas, sensibles y afectivas que apuntan a una traslación de los espacios de la diáspora (Lao-Montes, 2007) hacia una diaspora estética (Peffer, 2013), reensamblando recursos de montaje propios de la nouvelle vague con un dispositivo político y social de visibilidad (Rancière, 2001) que se reconoce emancipatorio en tanto capaz de suspender la lógica opresor-oprimido y desafiar los dispositivos policiales (Ibíd.) de las estructuras coloniales.

\section{Conclusiones}

El papel de la ficción en el filme no es el de la evasión, sino que construye una «ficción documental» (Rancière, 2001) que genera correspondencias con su presente. Mediante una serie de signos culturales y políticos que se tensan con un contexto de descolonización, la película reensambla escenas de género en comunidades tradicionales -respondiendo a una lógica representacional y documental- con reencadenamientos de corte irracional (Deleuze, 1985) explorando nuevas formas de identificación cultural (Chérel, 2015) no sujetas a identidades políticas previamente constituidas ni a formatos visuales previsibles. Este entrelazamiento genera una imagen-tiempo (Deleuze, 1985) que no conserva, sino que crea una memoria (Rancière, 2001) sensible de un contexto en plena transformación.

En la película hay una traslación de las imágenes de la diáspora (Lao-Montes, 2007) hacia una «diáspora estética» (Peffer, 2013). Los espacios de la diáspora y de la migración se reelaboran, no desde un régimen representacional (Rancière, 2011), sino estético (Ibíd.); reapropiándose de recursos técnicos, visuales y poéticos propios de la nouvelle vague y generando un dispositivo político y social de visibilidad (Rancière, 2001) que subvierte las formas preestablecidas y consensuadas de narrar estos desplazamientos y procesos.

Mambéty reconduce la politización del cine, no hacia su cualidad discursiva, sino estética (Rancière, 2005). Ya no son las imágenes documentales que pretenden dotar de «mayor realidad» (Sontag, 2003) a una situación determinada, propias del cine militante o del Tercer Cine (Getino; Solanas, 1969); sino, por el contrario, la correspondencia entre formas de identificación poéticas y estéticas capaces de abandonar por completo el espacio dialéctico amo-esclavo (Han, 2005) y desafiar los dispositivos policiales (Rancière, 2003) de la subalternidad colonial (Spivak, 1985), no desde el gran relato revolucionario, sino desde una narrativa de situaciones sucintas: la de una inminencia del deseo como modo impulsivo y corpóreo de interrogación (Butler, 1987), y la de una estética radical que redefine tejidos sensibles sobre un espacio político común (Rancière, 2005).

\section{Referencias}

AbDERreZAK, H. (2016) Ex-centric migrations. Europe and the Maghreb in mediterranean cinema, literature, and music. Indiana University Press.

AFRICINE. Africine. Le site de la federation africaine de la critique cinématographique. <africine.org> [Consulta: septiembre 2019] [institucional]

ButLER, J. (1987) Sujetos del deseo. Reflexiones hegelianas en la Francia del siglo XX. Buenos Aires: Amorrortu Editores.

ChÉREL, E. (2015) L’energie radicale de Touki Bouki. Multitudes, 2015/1 (58), pp. 33-40.

DeleuZE, G. (1983) La imagen-movimiento. Estudios sobre cine 1. Barcelona: Paidós. 
DELEUZE, G. (1985) La imagen-tiempo. Estudios sobre cine 2. Barcelona: Paidós.

DeleuZe, G. (1988) Le pli. Leibniz et le baroque. París: Éditions de Minuit.

Frank-Ukadike, N. (1999) The Hyena’s Last Laugh [interview with Djibril Diop Mambety], Transition 78, Núm. 2 (8) pp. 136-153. Dubois Institute and Indiana University Press

FrEIRE, P. (1968) Pedagogía del oprimido. Madrid: Siglo XXI.

Getino, O.; Solanas, F. (1982) A diez años de "hacia un tercer cine”. México: Filmoteca de la UNAM.

HAN, B. (2005) Hiperculturalidad. Barcelona: Herder.

LAO-Montes, A. (2007) Avanços descoloniais. "Translocalizando" os espaços da diáspora africana. En Cultural Studies 2007 (21), 2-3, pp. 309-338.

PefFer, J. (2013) La diaspora des images de l'Afrique, Multitudes, 2013, 54, pp. 54-63.

RANCIÈRE, J. (2001) La fábula cinematográfica: reflexiones sobre la ficción en el cine. Barcelona: Paidós.

RANCIERE J. (2003) Aux bords du politique, Paris: Folio.

RANCIÈRE J. (2005) Sobre políticas estéticas, Barcelona: Museu d'Art Contemporani de Barcelona, Servei de Publicacions de la Universitat Autònoma de Barcelona.

RANCIÈRE, J. (2010) El espectador emancipado. Ellago Ediciones: Pontevedra.

RANCIERE, J. (2011) Aisthesis: scènes du régime esthétique de l'art. Paris: Galilée.

Rancière, J.; Soto-CAlderón, A.; BASSAs, X. (2018) Política del sentido: litigios de la imagen y el lenguaje. La Virreina Centre de la Imatge. Barcelona.

SonTAg, S. (2003) Ante el dolor de los demás. Madrid: Santillana.

Soto-CALDERón, A. (2013) J. Rancière - J.F. Lyotard: Efectos emancipatorios del arte en la crítica social. Disturbis. 2013 (14), pp. 1-13.

SpIVAK, G. C. (1985) Subaltern Studies: Deconstructing historiography, en Ranajit Guha (ed.), Subaltern Studies IV: Writings on South Asian History and Society. Delhi: Oxford University Press, pp. 330-363.

Touki Bouki (Dir. Djibril Diop Mambéty). Cinegrit / Studio Kankourama. 1973.

Veliz, M. (2010) El cine militante latinoamericano y la narrativa contrahistórica. En Revista Lindes. Estudios sociales del arte y la cultura. 2010 (1), 1, pp. 10-22. 